\title{
Azumiobodo hoyamushi gen. nov. et sp. nov. (Euglenozoa, Kinetoplastea, Neobodonida): a pathogenic kinetoplastid causing the soft tunic syndrome in ascidian aquaculture
}

\author{
Euichi Hirose ${ }^{1}$, Akino Nozawa ${ }^{2,3}$, Akira Kumagai ${ }^{4}$, Shin-Ichi Kitamura ${ }^{2,3, *}$ \\ ${ }^{1}$ Department of Chemistry, Biology and Marine Science, University of the Ryukyus, Nishihara, Okinawa 903-0213, Japan \\ ${ }^{2}$ Department of Biology, Faculty of Science, Ehime University, Matsuyama, Ehime 790-8577, Japan \\ ${ }^{3}$ Centre for Marine Environmental Studies (CMES), Ehime University, Matsuyama, Ehime 790-8577, Japan \\ ${ }^{4}$ Miyagi Prefecture Fisheries Technology Institute, Ishinomaki, Miyagi 986-2135, Japan
}

\begin{abstract}
We used morphological and genetic analyses to investigate a pathogenic kinetoplastid isolated from a diseased edible ascidian Halocynthia roretzi with soft tunic syndrome. The morphological characteristics of the kinetoplastid are similar to those in the order Neobodonida in the subclass Metakinetoplastida. However, the presence of unique globular bodies distinguishes this kinetoplastid from the other polykinetoplastic genera (i.e. Cruzella, Dimastigella and Rhynchobodo) in this order. These globular bodies are cytoplasmic inclusions without an outer delimiting membrane and are composed of a homologous granular matrix containing electron-dense bands. A phylogenetic tree based on 18S rRNA gene sequences also indicated that the kinetoplastid belongs to the order Neobodonida, although it forms an independent clade in this order. From these results, we propose a new genus in the order Neobodonida, i.e. Azumiobodo gen. nov., and Azumiobodo hoyamushi as the type species for the genus.
\end{abstract}

KEY WORDS: New kinetoplastid · Neobodonida $\cdot$ Azumiobodo $\cdot$ Pathogenic $\cdot$ Soft tunic syndrome $\cdot$ Ascidian aquaculture

\section{INTRODUCTION}

Soft tunic syndrome, an infectious disease of the edible ascidian Halocynthia roretzi (Drasche), causes mass mortality in aquaculture in Korea and Japan (e.g. Jung et al. 2001). In the diseased ascidians, the tunics become abnormally thin and soft; the ascidian then dies when the tunic tears. Several attempts have been made to identify the causative agent, and the pathogenic organism of the disease has recently been identified (Jung et al. 2001, Choi et al. 2006, Azumi et al. 2007a,b, Hirose et al. 2009, Kitamura et al. 2010). Kumagai et al. (2010) induced experimental infections by incubating healthy individuals with pieces of softened tunics and found flagellates in the softened tunic. The flagellates were found to fulfill Koch's postulates as the etiological agent of soft tunic syndrome (Kumagai et al. 2011).

These pathogenic flagellates are kinetoplastides that have 2 flagella and multiple kinetoplasts in the cytoplasm. At the electron microscope level, the flagellate is characterized by unique globular bodies composed of a homologous granular matrix containing electron-dense bands. Flagellate cells with the same morphology were also found in the softened tunic (Kumagai et al. 2011). We established a stable pure culture of these kinetoplastids, and their fine structure and molecular phylogeny inferred from $18 \mathrm{~S}$ 
rRNA gene sequences indicated their novel nature. Here, we propose a new genus in the order Neobodonida and describe the present kinetoplastid as a new species, Azumiobodo hoyamushi sp. nov., as the type species for the genus.

\section{MATERIALS AND METHODS}

\section{Flagellate isolate}

The flagellate was isolated from a diseased ascidian reared in the vicinity of Samenoura, Miyagi Prefecture, Japan (Kumagai et al. 2011). Cloning of the isolate was performed using the methods of Jung et al. (2005). The isolate was cloned at least 5 times by the limiting dilution method in maintenance medium $(10 \%[\mathrm{w} / \mathrm{v}]$ minimum essential medium [MEM], $2.5 \%$ [v/v] fetal bovine serum [FBS], 5 mM HEPES, $2 \mathrm{mM}$ L-glutamine, $2 \mathrm{mM}$ sodium bicarbonate and $1 \%$ [v/v] penicillin-streptomycin mixed solution prepared in artificial seawater) in 24-well tissue culture plates. The cloned flagellate was subcultured 40 times and maintained in $25 \mathrm{~cm}^{2}$ or $75 \mathrm{~cm}^{2}$ culture flasks to produce $\sim 10^{5}$ to $10^{6}$ cells $\mathrm{ml}^{-1}$.

\section{Microscopy}

The kinetoplastid cells were fixed with $0.3 \%$ formalin solution made in phosphate-buffered saline before measuring the lengths of the flagella and cell body. The freshly fixed cells were observed under a light microscope and photographed with a digital camera. Twenty cells were selected to provide a sufficient number of cells for measurement after abnormally shaped specimens had been eliminated. Cell lengths were measured with imaging software (DP2BSW, Olympus).

For closer morphological observation, the kinetoplastid cells in culture were briefly rinsed with MEM without FBS, concentrated by centrifugation $(2000 \times$ $g, 10 \mathrm{~min}$ ) and fixed with $2.5 \%$ glutaraldehyde in $0.45 \mathrm{M}$ sucrose solution buffered with $0.1 \mathrm{M}$ sodium cacodylate $(\mathrm{pH} 7.4)$. After a brief rinse with $0.45 \mathrm{M}$ sucrose in $0.1 \mathrm{M}$ sodium cacodylate buffer, the precipitate was post-fixed with $1 \%$ osmium tetroxide made in $0.1 \mathrm{M}$ cacodylate buffer for $2 \mathrm{~h}$ on ice and dehydrated through a graded ethanol series. The precipitate was cut into pieces with a razor blade and processed for light microscopy (LM), scanning electron microscopy (SEM) and transmission electron microscopy (TEM).
For LM, a piece of precipitate was mounted on a microscope slide with CMCP-10 High Viscosity Mountant (Polysciences) and gently squashed with a coverslip. The preparation was observed under a light microscope equipped with differential interference contrast (DIC) optics. Several DIC photomicrographs were combined to increase the depth of field by using the image post-processing software Helicon Focus Pro 4.2.7 (Helicon Soft).

For SEM, some parts of the precipitate were immersed in $t$-butanol and freeze-dried. The dried specimens were sputter-coated with gold-palladium and examined with a JEOL JSM-6060LV scanning electron microscope at $15 \mathrm{kV}$.

For TEM, pieces of precipitates were cleared with $n$-butyl glycidyl ether, embedded in epoxy resin and then sectioned at 70 to $100 \mathrm{~nm}$ thickness. Sections were stained with lead citrate and uranyl acetate and examined with a JEOL JEM-1011 transmission electron microscope at $80 \mathrm{kV}$.

\section{DNA extraction and PCR amplification}

Cultured flagellates $\left(\sim 10^{5}\right.$ cells $\left.\mathrm{ml}^{-1}\right)$ were harvested by centrifugation at $500 \times g$ for $5 \mathrm{~min}$, washed with MEM without FBS and suspended in $100 \mu \mathrm{TE}$ buffer (10 mM Tris-HCl, 1 mM EDTA, pH 8.0). The flagellates were completely lysed with a lysis buffer (0.2 $\mathrm{M} \mathrm{NaOH}$ and $1 \%$ sodium dodecyl sulphate [SDS]) at $55^{\circ} \mathrm{C}$ for $10 \mathrm{~min}$. Total nucleic acids were extracted by the phenol-chloroform extraction method. Forward (5'-ACC TGG TTG ATC CTG CAG T-3') and reverse universal primers (5'-TGA TCC TTC TGC AGG TTC ACC TAC-3') designed by Sogin (1990) were used to amplify the 18S rRNA gene. The PCR reaction was carried out for 40 cycles in a thermal cycler at $93.5^{\circ} \mathrm{C}$ for $30 \mathrm{~s}, 50^{\circ} \mathrm{C}$ for $30 \mathrm{~s}$ and $72^{\circ} \mathrm{C}$ for $2 \mathrm{~min}$. The purity and size of the amplified products were analyzed by electrophoresis on $2 \%$ agarose gels. The gels were stained with ethidium bromide and visualized under UV light.

The amplified PCR products were purified using the MinElute PCR Purification Kit (Qiagen). The purified PCR products were cloned using the pGEM$\mathrm{T}$ easy vector system (Promega) following the standard protocols according to the manufacturer's instructions, and Escherichia coli JM109 (TaKaRa) was transformed with the plasmid. Cloned plasmid was purified with a PureLink Quick Plasmid Miniprep Kit (Invitrogen) for sequencing. Sequencing was performed with a BigDye Terminator Cycle Sequencing FS Ready Reaction Kit (Applied Biosys- 
tems) and the universal primer set of M13 forward and M13 reverse. To obtain the full sequence, sequencing with an internal primer (5'-CGT TTG GAA GTT GCA ATG GG -3') was performed.

\section{Phylogenic analysis}

Nucleotide sequences were assembled using the program Genetyx-Win (v. 5.1), and the DNA sequences were aligned using the program CLUSTALX (Thompson et al. 1997) to search for an optimal phylogenetic tree with neighbor-joining criteria. The final phylogenetic tree was drawn with the MEGA 3.0 program (Kumar et al. 1994). For comparison, 18S rRNA gene nucleotide sequences of 49 isolates of Kinetoplastea from the DNA Data Bank of Japan (DDBJ), GenBank and the European Molecular Biology Laboratory (EMBL) database were used in this study.

\section{RESULTS \\ Description}

Azumiobodo gen. nov.

Diagnosis: Solitary flagellate with several kinetoplasts and globular bodies composed of a homologous granular matrix containing electron-dense bands. Basal part of anterior flagellum attached alongside rostrum-bearing cytosome. Posterior flagellum often attached to body but not always. Two flagella originate at an acute angle to each other.

Type species: Azumiobodo hoyamushi sp. nov.

Remarks: The presence of the globular bodies with electron-dense bands discriminates the new genus from the other polykinetoplastic neobodonids, i.e. Cruzella, Dimastigella and Rhynchobodo.

Etymology: The generic name is dedicated to Dr. K. Azumi, Hokkaido University, who organized the biological research team for countermeasures against soft tunic syndrome. Gender is masculine.

\section{Azumiobodo hoyamushi sp. nov.}

Type host: Halocynthia roretzi (Drasche)

Type locality: Samenoura, Miyagi Prefecture, Japan

Site of tissue development: tunic

Type material: Syntype specimens mounted for LM and those embedded in epoxy resin for EM were deposited in the National Museum of Nature and Science, Tokyo (NSMT), as NSMT NSMT-Pr 315.

Etymology: 'hoyamushi' is the nickname of this flagellate in Japanese: 'hoya' means ascidians and 'mushi' means bugs.

The kinetoplastid was fusiform, with a mean \pm SD length of $15.3 \pm 2.06 \mu \mathrm{m}(\mathrm{n}=20)$ and mean width of $4.7 \pm 0.95 \mu \mathrm{m}$ measured at the maximum width of the cell $(\mathrm{n}=20$ ) (Fig. 1A-D). The cells frequently contained round granules and/or vesicles, and occasionally a large clear vacuole (Fig. 1B). Two heterodynamic flagella emerged subapically (arrowheads in Fig. 1A-C): anterior flagellum (mean length $14.2 \pm$ $2.1 \mu \mathrm{m}, \mathrm{n}=20$ ) extended anteriorly, and the recurrent posterior flagellum (mean length $26.3 \pm 4.85 \mu \mathrm{m}, \mathrm{n}=$ 20) was often attached along the entire length of the cell body, becoming free at its posterior extremity. This flagellate swam by rolling or shaking the posterior end of the cell body and sometimes pivoted around the anterior part of the cell body by expanding and contracting its body. A small rostrum partly covered the basal part of the anterior flagellum. A nucleus with a distinct nucleolus and condensed peripheral chromatin was situated in the middle part of the cell (Fig. 1D).

The cell surface appeared smooth and was devoid of any extracellular covering such as lorica, scales or distinct glycocalyx coat. The plasma membrane was underlain by longitudinal pellicular microtubules arranged regularly (Fig. 2A,B). Both flagella emerged from the bottom of a subapical flagellar pocket (Fig. 2A). The cells exhibited a shallow ventral groove along which the posterior flagellum extended, and no adhesive structures were seen between the flagellum and cell body (Fig. 2B,C). Both flagella originated at an acute angle to each other (Fig. 2A). The paraxial rod was situated next to the axoneme of each flagellum (Fig. 2D). In some sections, a central filament was observed in the transition zone of the flagellar base (Fig. 2A). The cytostome was located at the apex of the small rostrum, which was an apical projection of the cell anterior to the flagellar pocket, and the rostrum partly covered the basal part of the anterior flagellum. The cytostome continued into the cytopharynx (Fig. 2E). Posterior to the cytostome, phagosome-like vacuoles sometimes contained fuzzy homogeneous materials and membranous materials (Fig. 2F). No intracellular bacteria were observed in the cytoplasm.

Multiple kinetoplasts were well developed in the cells, whereas fine structures of mitochondria were not well preserved (Fig. 3A,B). Small globular 

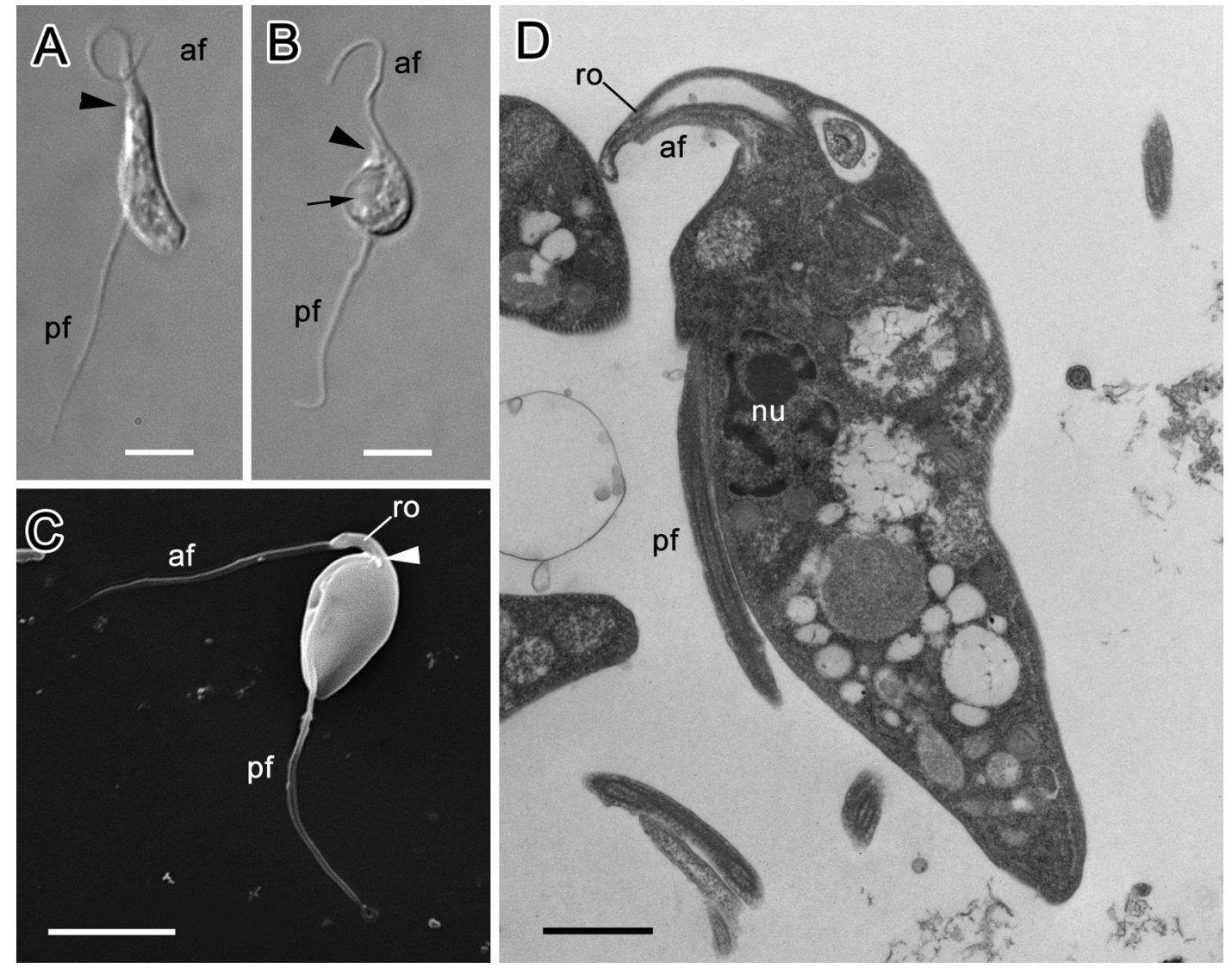

Fig. 1. Azumiobodo hoyamushi sp. nov. (pure culture in vitro). (A,B) Whole-mount photomicrographs with differential interference optics (DIC) optics. The cells were usually fusiform (A) and occasionally oval, with a large vacuole (arrow in B). (C) Scanning electron microscopy image of the whole cell. Posterior flagellum extending along the cell body. (D) Transmission electron microscopy (TEM) image of semi-longitudinal section of the cell. The nucleus (nu) had a prominent nucleolus. Arrowheads (A-C) indicate the emerging point of the 2 flagella. af: anterior flagellum; pf: posterior flagellum; ro: rostrum. Scale bars $=5 \mu \mathrm{m}$ in $\mathrm{A}-\mathrm{C}, 1 \mu \mathrm{m}$ in $\mathrm{D}$

organelles, $\sim 0.2 \mu \mathrm{m}$ in diameter, bound by a single membrane, were present in the cytoplasm (Fig. 3). These organelles were filled with homologous electron-dense material and corresponded to the glycosome. Clear vesicles $\sim 0.5 \mu \mathrm{m}$ diameter were often found in the cytoplasm, whereas lipoidal globules were rarely observed. In addition, the flagellate possessed unique globular bodies (Fig. 3C). The globular body was a cytoplasmic inclusion without an outer delimiting membrane and was composed of a homologous granular matrix containing electron-dense bands. Several electron-dense bands were arranged nearly parallel and concentric to each other in a moderately electron-dense globule (Fig. 3C).

In hospite, the kinetoplastids are fusiform, retain the flagella and have mitochondria with multiple kinetoplasts and globular bodies with the electrondense bands (Figs. 2 \& 3 in Kumagai et al. 2011).
They often form a loose aggregate in the disintegrating tunic matrix.

\section{Molecular phylogeny}

PCR amplification yielded $2101 \mathrm{bp}$ products except for the primer regions. The sequence was deposited in the DDBJ (accession number AB636162). A phylogenetic tree based on the gene nucleotide sequences revealed the following 5 major clades: the first clade contained isolates from the order Parabodonida, the second clade contained isolates from the order Eubodonida, the third from the order Trypanosomatida, the fourth clade from the order Neobodonida, and the final clade contained isolates from the order Prokinetoplastida, which were used as an outgroup (Fig. 4). The isolate, Azumiobodo hoya- 

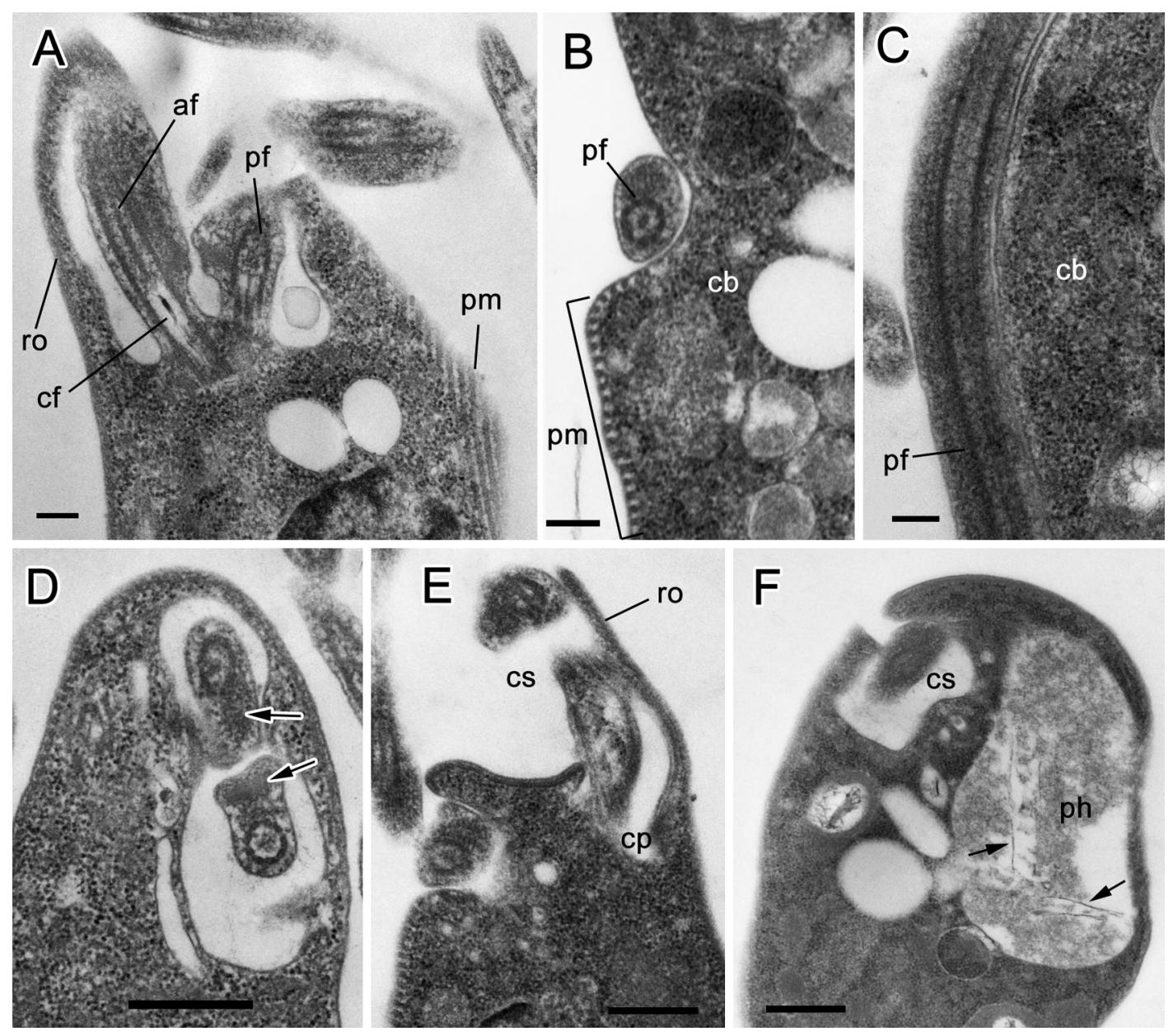

Fig. 2. Azumiobodo hoyamushi sp. nov. (pure culture in vitro). TEM images of subcellular structures. (A) The 2 flagella emerging from the bottom of the flagellar pocket. A central filament (cf) can be seen in the transition zone of the flagellar base. (B) Cross section of the posterior flagellum (pf) in a shallow groove on the cell body (cb), also showing pellicular microtubules (pm). (C) Longitudinal section of the posterior flagellum on the cell body (cb). (D) Cross sections of the 2 flagella in the flagellar pocket. Arrows indicate paraxial rods. (E) Cytosome (cs) and cytopharynx (cp). (F) A phagosome-like vacuole (ph) is shown containing fuzzy homogeneous materials; arrows indicate membranous materials. af: anterior flagellum; ro: rostrum. Scale bars $=0.2 \mu \mathrm{m}$ in $\mathrm{A}-\mathrm{C}, 0.5 \mu \mathrm{m}$ in $\mathrm{D}-\mathrm{F}$

mushi sp. nov., used in the present study appeared in the order Neobodonida, and the sequence of the isolate showed higher sequence similarities (>90\%) with an uncultured bodonid clone AT5-48 (91\%) and with Cruzella marina (90\%). However, according to the phylogenetic analysis, these 3 sequences did not fall into 1 clade, and A. hoyamushi sp. nov. formed an independent clade (1000 bootstrap replicates) (Fig. 4).

\section{DISCUSSION}

On the basis of cytomorphology and molecular phylogeny, we propose a new genus Azumiobodo in the order Neobodonida for the type species, Azumiobodo hoyamushi sp. nov., a protistan pathogen that causes soft tunic syndrome in the edible ascidian Halocynthia roretzi (Kumagai et al. 2011). The new species is the only pathogenic kinetoplastean isolated from ascidians to date. It was isolated from the tunic of the diseased ascidian, and a stable pure culture was established in vitro. However, the life history of this new species is not yet fully described. To develop countermeasures against the spread of soft tunic syndrome, it is necessary to find the natural habitat of the pathogen outside the host.

Several molecular phylogenies have indicated that the suborder Bodonia in the order Kinetoplastida is a paraphyletic assemblage, and on this basis 


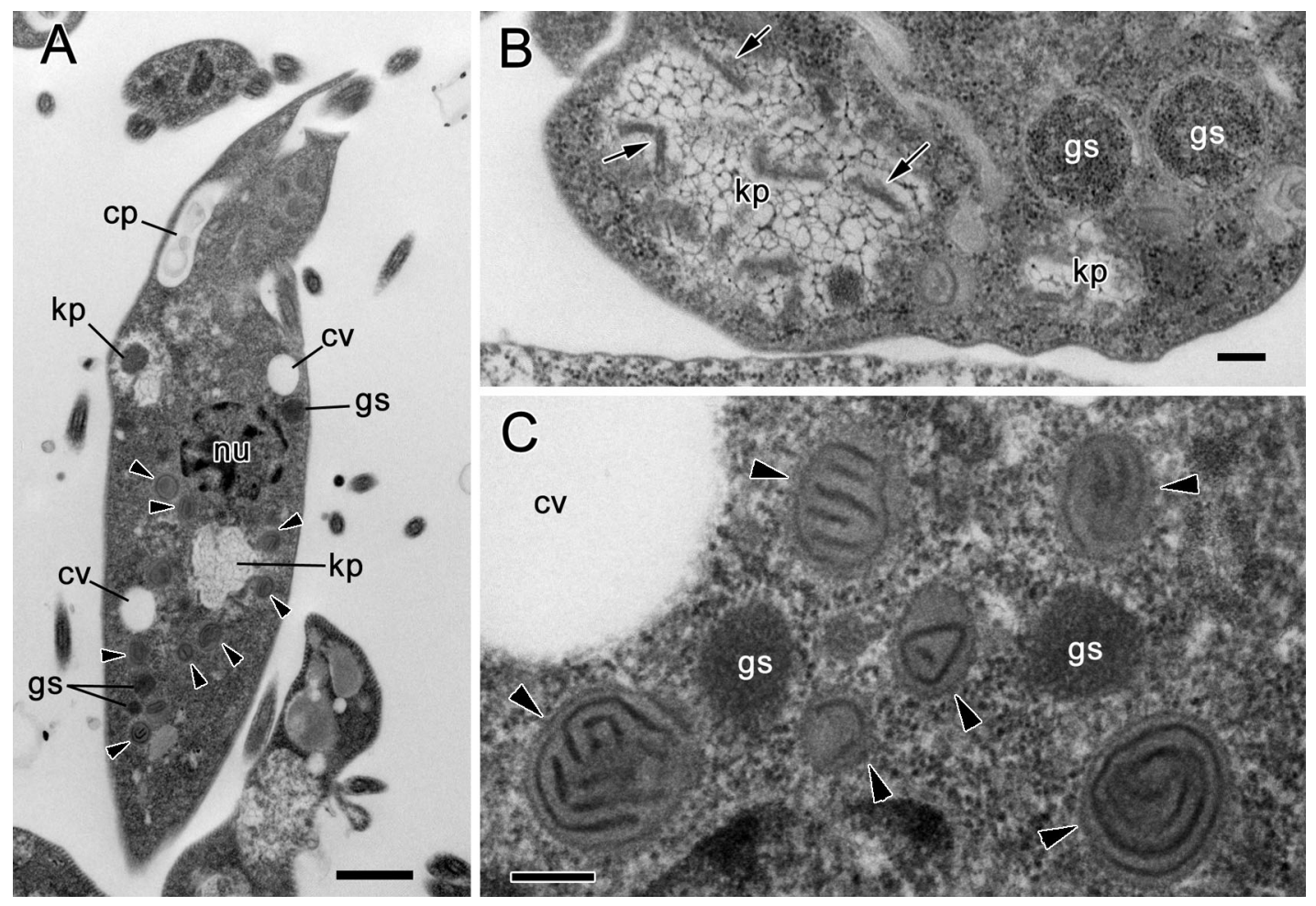

Fig. 3. Azumiobodo hoyamushi sp. nov. (pure culture in vitro). Kinetoplasts and granular contents. (A) Semi-longitudinal section of the cell body showing 2 kinetoplasts (kp), glycosomes (gs), clear vesicles (cv) and globular bodies with electron-dense bands (arrowheads). Some vesicular materials were found in the cytopharynx (cp): nucleus. (B) Enlargement of kp and gs. Arrows indicate the remnants of the mitochondrial cristae. (C) Enlargement of globular bodies with electron-dense bands (arrowheads). Scale bars $=1 \mu \mathrm{m}$ in $\mathrm{A}, 0.2 \mu \mathrm{m}$ in $\mathrm{B}, \mathrm{C}$

a major revision of kinetoplastid systematics has been recommended (e.g. Maslov et al. 2001, Simpson et al. 2002). Based on 18S rRNA gene phylogeny, Moreira et al. (2004) divided the class Kinetoplastea into 2 subclasses (i.e. Prokinetoplastida and Metakinetoplastida), and our 18S rRNA gene phylogeny has indicated that Azumiobodo gen. nov. is a member of the latter subclass. Azumiobodo gen. nov. is polykinetoplastic and has a conspicuous rostrum, and these character traits agree with those of Neobodonida, which is one of the 4 orders in Metakinetoplastida. This is consistent with our phylogenetic tree of the kinetoplastean 18S RNA gene sequence. The presence of unique globular bodies with electron-dense bands discriminates Azumiobodo gen. nov. from the other polykinetoplastic genera (i.e. Cruzella, Dimastigella and Rhynchobodo) in Neobodonida. In Azumiobodo gen. nov., the flagellar bases are positioned at an acute angle to one another and an anterior flagellum attains a similar length to the cell body; these features also distinguish Azumiobodo gen. nov. from both Dimastigella and Rhynchobodo (see Vickerman 2000).
Although the original description of the genus Cruzella was too simple to distinguish it from other kinetoplasteans (De Faria et al. 1922), the monotypic species C. marina is the closest relative of Azumiobodo gen. nov., except for an uncultured bodonid clone AT5-48 detected in hydrothermal sediment (López-García et al. 2003), as shown in Fig. 4. Considerable similarities and differences in ultrastructure exist between the new species and $C$. marina (see Frolov \& Malysheva 2002). Both species have a central filament in the transition zone of each flagellar base, which possibly supports their close relationship. In contrast, pellicular microtubules line the whole cell body in the new species, but in C. marina these microtubules are found only at the anterior end.

Our phylogenetic tree, inferred from 18S RNA gene sequences, is essentially consistent with other kinetoplastean trees (Moreira et al. 2004, Stoeck et al. 2005), although Neobodonida is a paraphyletic clade in our tree (Fig. 4). As discussed in Moreira et al. (2004), Neobodonida is the most puzzling clade in the subclass Metakinetoplastina. Neobodonida 


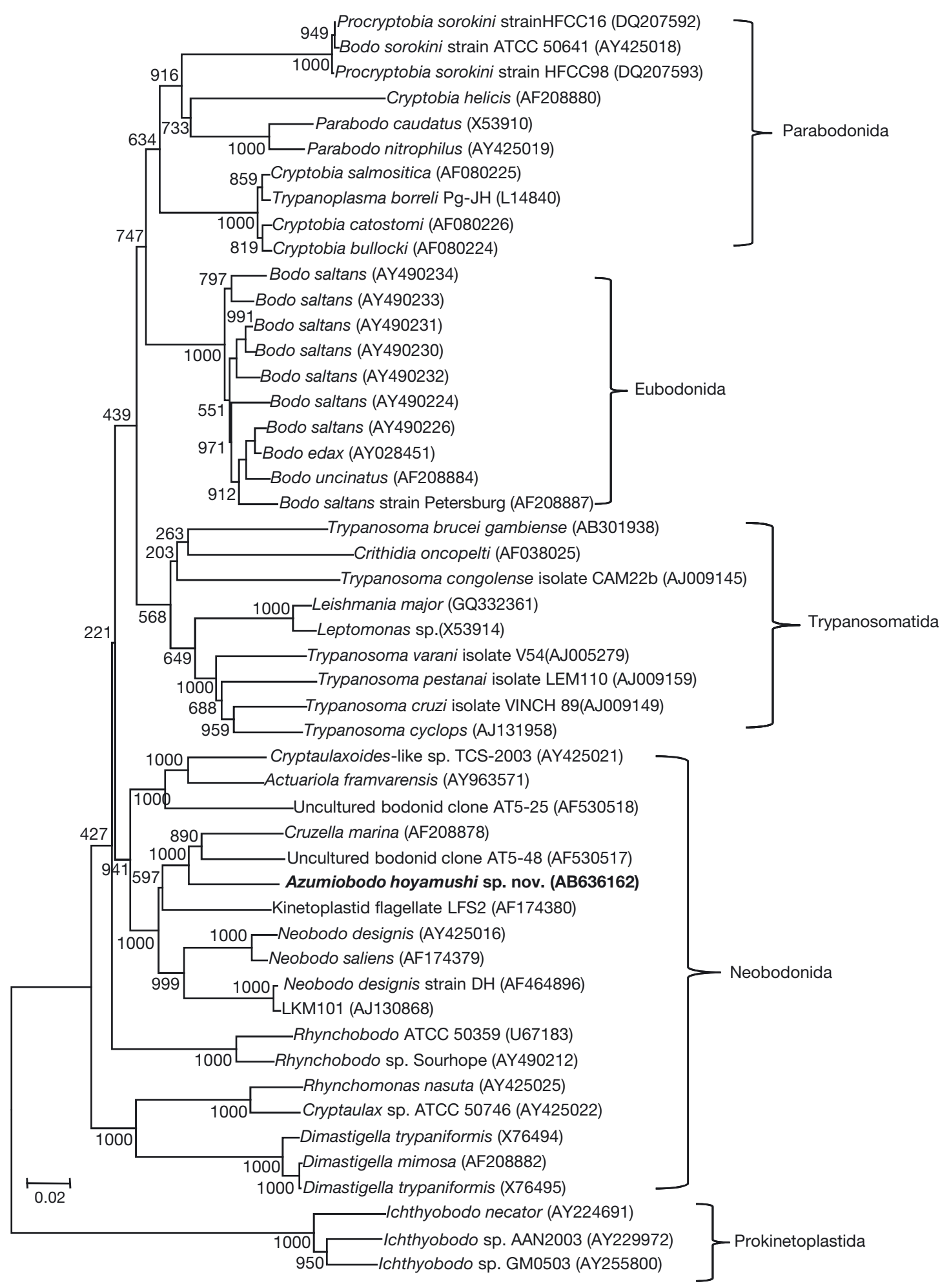

Fig. 4. Molecular phylogenetic tree for the genetic relationship among 50 isolates of Kinetoplastea based on the nucleotide sequence of the 18S rRNA gene. The bootstrap process was repeated 1000 times and the values are shown at major nodes in the tree. The scale bar is for a genetic distance marker (number of replacement nucleotides per site). DNA sequences were aligned using CLUSTALX, and the final phylogenetic tree was drawn in MEGA 3.0. Species names in the tree were taken from UniProt (www.uniprot.org/taxonomy/) 
potentially includes an early branched clade and/or a highly specialized clade in Metakinetoplastina. Cruzella marina often occupies a basal position in some kinetoplastean or metakinetoplastean trees (Maslov et al. 2001, Frolov \& Malysheva 2002, Simpson et al. 2002, 2006). Furthermore, Simpson et al. (2002) have suggested that another polykinetoplastic species potentially takes a basal position in the tree. Therefore, Azumiobodo hoyamushi sp. nov. may arise early in the metakinetoplastean lineage, since this polykinetoplastic species is a close relative of $C$. marina. In addition, the possibility exists that we have only dealt with the 'tip of the iceberg' and have only just begun to understand the real diversity of kinetoplasteans.

Obligate parasitism or commensalism is supposed to have independently evolved several times within kinetoplastids (e.g. Maslov et al. 2001, Simpson et al. 2006). In the order Neobodonida, most species are free living, and some are possibly endocommensal (Moreira et al. 2004). In our phylogenetic tree (Fig. 4), neobodonids closely affiliated with Azumiobodo hoyamushi sp. nov. are Cruzella marina, Neobodo designis and $N$. saliens, and these are also free-living species. In contrast, the present new species is the pathogen causing soft tunic syndrome, and thus transition from a free-living to parasitic life style probably occurred in an ancestor of this species.

We described the new species by using the stable cultured strain after subculturing $>40$ times. The morphology of these cultured cells was basically the same as that of the cells in hospite, and the cells appeared in seawater in which the diseased tunic pieces were incubated. These kinetoplastids, whether they were obtained from the host tissue or from culture, always contained the unique globular bodies with electron-dense bands.

However, some differences existed between the cells that were obtained in hospite and the cultured cells. Although the cell length in culture was $\sim 15 \mu \mathrm{m}$, lengths of uncultured cells ranged from 10 to $13 \mu \mathrm{m}$ (Kumagai et al. 2011). Besides the cell size, the nutritious culture conditions with MEM-FBS probably altered some subcellular morphology: the uncultured cells had no phagosomes or food vacuoles, their kinetoplasts were smaller than those of cultured cells and the mitochondria retained well-preserved ultrastructure with discoidal cristae (Kumagai et al. 2011). These cytomorphological differences were assumed to have been caused by the nutrient conditions and atmospheric oxygen concentration. Also, both cultured and uncultured cells were shown to cause soft tunic syndrome (Kumagai et al. 2011). What the pre- sent species feeds on in the ascidian tunic is still uncertain, but this could be a crucial key in solving the mechanism that softens the tunic. From this symptom of the disease, it is suspected that Azumiobodo hoyamushi sp. nov. secretes cellulase and/or proteinase, which collapses the protein or proteins, that crosslink cellulose fibrils of the host tunic. If this is true then future research could focus on these extracellular enzymes as the mechanism that causes soft tunic syndrome.

Acknowledgements. We thank Dr. K. Azumi, Hokkaido University, and Dr. S.-I. Otake, Nihon University, for their valuable discussions on the ascidian biology and pathology. Thanks also go to Dr. T. Nakayama, University of Tsukuba, for valuable advice on the taxonomy of kinetoplastids. The flagellate was isolated from a diseased ascidian cultured in the region devastated by the Tohoku Region Pacific Coast earthquake in Japan. We sincerely commemorate the victims of this disaster and hope for reconstruction of the areas affected.

\section{LITERATURE CITED}

Azumi K, Nakamura S, Kitamura SI, Jung SJ and others (2007a) Accumulation of organotin compounds and marine birnavirus detection in Korean ascidians. Fish Sci 73:263-269

Azumi K, Usami T, Kamimura A, Sabau SV and others (2007b) cDNA microarray analyses reveal candidate marker genes for the detection of ascidian disease in Korea. Zool Sci 24:1231-1240

> Choi DL, Jee BY, Choi HJ, Hwang JY, Kim JW, Berthe FCJ (2006) First report on histology and ultrastructure of an intrahemocytic paramyxean parasite (IPP) from tunicate Halocynthia roretzi in Korea. Dis Aquat Org 72:65-69

> De Faria JG, Cunha AM, Pinto C (1922) Estudos sobre protozoairos do mar. Mem Inst Oswaldo Cruz 15:186-208

Frolov AO, Malysheva MH (2002) Ultrastructure of the flagellate Cruzella marina (Kinetoplastida). Tsitologia 44: 477-484 (in Russian)

Hirose E, Ohtake SI, Azumi K (2009) Morphological characterization of the tunic in the edible ascidian, Halocynthia roretzi (Drasche), with remarks on 'soft tunic syndrome' in aquaculture. J Fish Dis 32:433-445

Jung SJ, Oh MJ, Date T, Suzuki S (2001) Isolation of marine birnavirus from sea squirts Halocynthia roretzi. In: Sawada H, Yokosawa H, Lambert CC (eds) The biology of ascidians. Springer-Verlag, Tokyo, p 436-441

Jung SJ, Kitamura SI, Song JY, Joung IY, Oh MJ (2005) Complete small subunit rRNA gene sequence of the scuticociliate Miamiensis avidus pathogenic to olive flounder Paralichthys olivaceus. Dis Aquat Org 64:159-162

Kitamura SI, Ohtake SI, Song JY, Jung SJ and others (2010) Tunic morphology and viral surveillance in diseased Korean ascidians: soft tunic syndrome in the edible ascidian, Halocynthia roretzi (Drasche), in aquaculture. J Fish Dis 33:153-160

Kumagai A, Suto A, Ito H, Tanabe T, Takahashi K, Kamaishi T, Miwa S (2010) Mass mortality of cultured ascidians 
Halocynthia roretzi associated with softening of the tunic and flagellate-like cells. Dis Aquat Org 90:223-234

Kumagai A, Suto A, Ito H, Tanabe T and others (2011) Soft tunic syndrome in the edible ascidian Halocynthia roretzi is caused by a kinetoplastid protist. Dis Aquat Org 95:153-161

Kumar S, Tamura K, Nei M (1994) MEGA: molecular evolutionary genetics analysis software for microcomputers. Comput Appl Biosci 10:189-191

López-García P, Philippe H, Gail F, Moreira D (2003) Autochthonous eukaryotic diversity in hydrothermal sediment and experimental microcolonizers at the MidAtlantic Ridge. Proc Natl Acad Sci USA 100:697-702

Maslov DA, Podlipaev SA, Lukesý J (2001) Phylogeny of the Kinetoplastida: taxonomic problems and insights into the evolution of parasitism. Mem Inst Oswaldo Cruz 96: 397-402

Moreira D, López-García P, Vickerman K (2004) An updated view of kinetoplastid phylogeny using environmental sequences and a closer outgroup: proposal for a new classification of the class Kinetoplastea. Int J Syst Evol Microbiol 54:1861-1875

Simpson AGB, Lukesý J, Roger AJ (2002) The evolutionary history of kinetoplastids and their kinetoplasts. Mol Biol Evol 19:2071-2083

Editorial responsibility: Dieter Steinhagen,

Hannover, Germany
Simpson AGB, Stevens JR, Lukesý J (2006) The evolution and diversity of kinetoplastid flagellates. Trends Parasitol 22:168-174

Sogin ML (1990) Amplification of ribosomal RNA genes for molecular evolution studies. In: Innis MA, Gelfand DH, Sninsky JJ, White TJ (eds) PCR protocols: a guide to methods and applications. Academic Press, San Diego, CA, p 307-314

> Stoeck T, Schwarz MVJ, Boenigk J, Schweikert M, von der Heyden S, Behnke A (2005) Cellular identity of an $18 \mathrm{~S}$ rRNA gene sequence clade within the class Kinetoplastea: the novel genus Actuariola gen. nov. (Neobodonida) with description of the type species Actuariola framvarensis sp. nov. Int J Syst Evol Microbiol 55: 2623-2635

Thompson JD, Gibson TJ, Plewniak F, Jeanmougin F, Higgins DG (1997) The CLUSTAL_X windows interface: flexible strategies for multiple sequence alignment aided by quality analysis tools. Nucleic Acids Res 25: 4876-4882

Vickerman K (2000) Order Kinetoplastea Honigberg, 1963. In: Lee JJ, Leedale GF, Bradbury P (eds) An illustrated guide to the protozoa: organisms traditionally referred to as protozoa or newly discovered groups. Allen Press, Lawrence, KS, p 1159-1185

Submitted: June 6, 2011; Accepted: October 28, 2011 Proofs received from author(s): January 15, 2012 